\title{
Uptake of non-invasive prenatal testing (NIPT) and impact on invasive procedures in a tertiary referral center
}

\author{
Gwendolin Manegold-Brauer · C. Berg • \\ A. Flöck · A. Rüland $\cdot$ U. Gembruch . \\ A. Geipel
}

Received: 22 January 2015/ Accepted: 16 February 2015/Published online: 26 February 2015

(C) Springer-Verlag Berlin Heidelberg 2015

\begin{abstract}
Purpose The introduction of non-invasive prenatal testing (NIPT) by isolation of cell-free fetal DNA from maternal blood is a new diagnostic option in prenatal care. The aim of the study was to investigate the algorithm of prenatal testing before and after the introduction of NIPT in a tertiary referral center and to investigate the influence of NIPT on the frequency of invasive procedures.

Methods Retrospective data analysis was conducted of all singleton pregnancies that presented for first trimester screening 17 months before and after the introduction of NIPT $(n=2271)$. Women were categorized into three risk groups: low risk for trisomy $21(<1: 1000)$, intermediate risk (1:101-1:1000) and high risk ( $\geq 1: 100)$. The choice of diagnostic testing after FTS was analyzed.

Results 1093 (group 1) presented before and 1178 (group 2) after the introduction of NIPT. The rate of high-risk patients was equal in both groups (14.4 vs. $15.4 \%)$. No differences were found with regard to invasive testing (11.6 vs. $11.3 \%)$. NIPT was chosen by $3.7 \%(44 / 1178)$ in group 2. Of those with NIPT, $72.7 \%$ had a risk estimate of
\end{abstract}

G. Manegold-Brauer $(\bowtie) \cdot$ C. Berg · A. Flöck · A. Rüland ·

U. Gembruch · A. Geipel

Department of Obstetrics and Prenatal Medicine, University

Medical School Bonn, Sigmund-Freud-Str. 25, 53105 Bonn,

Germany

e-mail: gwendolin.manegold-brauer@usb.ch

G. Manegold-Brauer

Department of Prenatal Medicine and Gynecologic Ultrasound,

University Medical School Basel, Basel, Switzerland

C. Berg

Department of Obstetrics and Gynecology, Division of Prenatal Medicine and Gynecologic Ultrasound, University Medical School Cologne, Cologne, Germany
$<1: 100$, but $90.9 \%$ were $\geq 35$ years old. The rate of NIPT among high-risk patients with a normal ultrasound examination was $25 \%$.

Conclusion At present, NIPT is chosen mainly for reassurance by patients not considered to be at high risk. In the high-risk group, NIPT can be offered if the ultrasound examination is normal and the risk is high due to maternal age or serum screening alone. The rate of invasive testing was not reduced in this selected population.

Keywords NIPT · NIPD - Cell-free fetal DNA · Fetal aneuploidies · Prenatal counseling · Non-invasive prenatal testing · Trisomy 21

\section{Introduction}

Non-invasive prenatal testing (NIPT), analyzing cell-free DNA from maternal blood, has added a new diagnostic option to prenatal medicine in developed countries [1-3]. At present, different tests are available from different commercial laboratories. Although rapidly incorporated in current first and second trimester screening strategies, its implementation in general prenatal care is debated controversially $[4,5]$. While some recommend testing in selected high-risk pregnancies only, others advocate offering NIPT to all pregnant women regardless of risk $[4,6,7]$. There is a general agreement that NIPT should be accompanied by adequate pre-test and post-test counseling [8-10]. Further, individual uptake is influenced by economic factors, and reimbursement of costs by the insurance companies is a significant issue for many women.

Traditional screening algorithms for autosomal trisomies are based on ultrasound and biochemical parameters and have reported detection rates of about $90 \%$ 
with false-positive rates of 3-5\% [11-13]. Especially, the introduction of first trimester screening (FTS) policies have led to a more individualized risk assessment and a decrease in invasive testing [14-17]. There are national screening programs in some countries, such as the UK and Denmark, but in many other countries including Germany, there are no national guidelines for screening and individual practitioners and centers provide a variety of tests with widely differing quality [18-20].

There is increasing worldwide evidence that NIPT has excellent sensitivity, specificity and negative predictive values for autosomal trisomies [21-28]. A recent meta-analysis provided pooled detection rates of $99.0 \%$ for trisomy 21 , $96.8 \%$ for trisomy 18 and $92.1 \%$ for trisomy 13 , with falsepositive rates (FPR) of 0.08-0.12\%, respectively [29]. One major advantage compared to classical FTS is the extremely low false-positive rate, hence requiring a much lower rate of follow-up invasive testing. At present, clinically available NIPT is focused mainly on trisomy 21,18 and 13 , which comprise only $70 \%$ of aneuploidies commonly detected by prenatal diagnosis [30].

There are a limited number of studies that demonstrate women's choices in daily clinical care. Furthermore, there are no data showing the uptake of NIPT in high-risk patients in correlation with specific ultrasound findings. The aim of this study therefore was to investigate the algorithm of prenatal testing before and after the introduction of NIPT in the first trimester in a high-risk collective and the influence of NIPT on invasive prenatal procedures.

\section{Materials and methods}

This is a retrospective analysis of all singleton pregnancies $(n=2271)$ that presented for a detailed FTS between 01/03/2011 and 31/12/2013 at the University Hospital Bonn (tertiary referral center). The patients are usually referred to our center with a special indication such as advanced maternal age, a personal or family history of genetic disease or birth defects or for a second opinion in cases of suspected sonographic abnormalities. FTS was offered as a combined test between 11 and 14 weeks of gestation and included a detailed examination of the fetal anatomy as well as assessment of nuchal translucency, nasal bone, the tricuspid valve and the ductus venosus blood flow. Maternal serum was evaluated for pregnancyassociated plasma protein A (PAPP-A) and free beta-HCG levels. 637 women declined the additional blood test. Therefore, risk calculation was performed on the basis of sonographic findings including serum biochemistry in 1634 patients and without biochemistry in 637 patients.

FTS was conducted by experienced certified specialists according to the guidelines of the Fetal Medicine
Foundation (FMF) London. Risk calculation was performed with the Viewpoint software (GE, Viewpoint Version 5.6.12.601, Wessling, Germany).

Non-invasive prenatal testing (NIPT) became clinically available in Germany in August 2012. The PraenaTest ${ }^{\circledR}$ (Lifecodexx, Konstanz, Germany) was the only NIPT test used in the study group. From August 2012 until February 2013 the PraenaTest ${ }^{\circledR}$ was offered for the detection of trisomy 21 only. Since February 2013, analysis for trisomy 13 and 18 also became available.

All women had a pre-test counseling about prenatal ultrasound screening, FTS and both invasive and non-invasive diagnostic procedures. Counseling included detailed information on the strengths, limitations, risks and costs of each method. Up to July 2012 NIPT was not available (group 1). From August 2012 onward, pre-test counseling included the option of NIPT (group 2). NIPT was offered as a screening test which would require an invasive procedure (IPT) for confirmation in cases of abnormal results. After FTS the patients were counseled again on the basis of their individual test results, including all the above-mentioned information with an individual risk-benefit analysis for further tests. There is no general reimbursement for FTS (approximately, $200 €$ ) or NIPT (approximately, $700 €$ ) by insurance companies in Germany. NIPT therefore was always performed at the patient's expense.

Women were categorized into three risk groups according to the results of FTS: (a) high risk $\geq 1: 100$; (b) intermediate risk 1:101-1:1000; (c) low risk for aneuploidy $<1: 1000$. NT $>95$ th percentile, presence of multiple soft markers (nasal bone, ductus venosus, tricuspid valve regurgitation, single umbilical artery, plexus choroideus cysts) or the presence of fetal structural abnormalities were considered as high risk, regardless of the risk calculation. Risk calculation was always performed for trisomy 21,18 and 13 individually. Women were grouped according to their risk for trisomy 21 unless the risk for trisomy 13/18 was higher (5 patients). The uptake of invasive prenatal testing (IPT) and non-invasive prenatal testing (NIPT) was investigated for each risk group a-c. Pregnancy outcome was obtained from routine newborn examination at the delivery units.

All statistical analyses were performed using $\mathrm{R}$ system for statistical computation Version 2.15.1. A $p$ value $<0.05$ was considered significant. Frequencies in the tables were compared using Chi-square test; if the frequency was less than 5 Fisher test was used.

\section{Results}

A total of 2271 patients were included in the study. 1093 examinations were conducted before NIPT was available 
(group 1) and 1178 patients presented after the introduction of NIPT (group 2). The comparison of the baseline characteristics regarding risk groups and maternal age revealed no statistically significant differences between both periods (Table 1). Overall, $15.0 \%(340 / 2271)$ had a high risk for trisomy 21 according to FTS. Of those, $24.4 \%(84 / 340)$ had a normal fetal assessment, $25.9 \%$ (88/340) showed multiple soft markers, $22.1 \%(75 / 340)$ had a nuchal translucency above the 95th percentile and $27.6 \%$ (94/ 340) presented with structural abnormalities. The mean maternal age was lower in the high-risk group compared to the intermediate-risk group (33.9 versus 37.0 years) (Table 1$)$. In group $1,14.4 \%$ of patients $(n=158)$ were considered high risk and a total of $11.6 \%(n=127)$ opted for IPT. Of those who chose IPT, 70.1\% belonged to the high-risk group and $29.9 \%$ had a risk of $<1: 100$ for trisomy 21 (Table 2).

In group 2, $15.4 \%(n=182)$ of the patients had a high risk for trisomy 21 , and the overall rate of IPT was $11.3 \%$ $(n=133) .72 .9 \%$ of the patients choosing IPT belonged to the high-risk group. No significant differences were seen with regard to IPT before and after the introduction of NIPT (11.6 vs. $11.3 \% ; p=0.652$ ). In group $2,3.7 \%$ (44/ $1178)$ of the patients voted for NIPT. The mean maternal age among them was 38 years and $90.9 \%$ (40/44) were $\geq 35$ years old. With regard to their risk distribution, $27.3 \%(12 / 44)$ had a risk of $\geq 1: 100$ and $72.7 \%(32 / 44)$ had a risk of $<1: 100$ (Table 2).

In patients with a risk of $>1: 1000$ (intermediate and high risk), the rates of IPT in groups 1 and 2 were not different (31.9 vs. $32.3 \%)$. NIPT was chosen by $8.6 \%$ (31/362) of those with high and intermediate risks in group 2, with $87.1 \%(27 / 31)$ of them having a normal fetal assessment. There was a significant decrease in patients who opted to have no further testing between group 1 and 2 (68.1 vs. $59.1 \% ; p=0.007$ ) with a risk estimation of $>1: 1000$. For the total study population, there was a significant increase in additional testing from $11.6 \%$ in group 1 (127/1093, IPT only) to $15.0 \%$ in group $2(177 / 1178$, IPT and NIPT) $(p=0.017)$ and this was solely caused by the application of NIPT (Table 2).
Table 3 summarizes individual findings of high-risk patients from group 2. Of those with a normal scan, $50 \%$ (16/32) decided for IPT, $25 \%$ (8/32) for NIPT and $25 \%$ (8/32) for no testing. On the other hand, of high-risk patients with sonographic findings, $54 \%$ chose IPT (81/150), $2.7 \%$ NIPT (4/150) and $43.3 \%$ no further testing $(65 / 150)$ (Table 3). There was a significant difference of NIPT uptake between patients with a normal scan and patients with sonographic findings $(p=0.00012)$.

We observed no false-positive or false-negative NIPT results in the study group. One test was positive for trisomy 21 and the diagnosis was later confirmed by amniocentesis. This patient had a combined risk of 1:104, but presented also with tricuspid valve regurgitation and was therefore considered high risk. In our study, NIPT did not lead to an increase in the overall detection of trisomy 21 compared to the conventional screening algorithm, which would recommend karyotyping in the high-risk group. Among patients who opted for IPT $(n=260), 26.5 \%(n=69)$ had an aneuploidy. While $66.7 \%$ (46/69) had either trisomy 21,18 or $13,33.3 \%(23 / 69)$ were diagnosed with other chromosomal abnormalities.

\section{Discussion}

This is the first study investigating the clinical uptake of NIPT in a German tertiary referral center. The reported data stem from a pre-selected high-risk population, where $15 \%$ of the referrals are considered high risk for aneuploidies. In contrast to most other screening studies including high-risk patients of advanced maternal age and/ or those with abnormal serum tests [31, 32], more than $80 \%$ of our pregnancies with a risk of $\geq 1: 100$ presented with sonographic abnormalities. This is also underlined by the fact that the median maternal age in the high-risk group was lower compared to the intermediate-risk group. It is therefore not surprising that the rate of invasive testing before and after the introduction of NIPT remained unchanged in our collective. Invasive testing was especially considered in those patients with structural anomalies or a

Table 1 Baseline characteristics of patients of the two study groups according to risk estimation after FTS: (a) High risk $\geq 1: 100$; (b) intermediate risk 1:1000-1:101; (c) low risk for aneuploidy $<1: 1000$

\begin{tabular}{|c|c|c|c|c|c|}
\hline \multirow[t]{2}{*}{ Risk group } & \multicolumn{2}{|c|}{ Group $1(n=1093)$} & \multicolumn{3}{|c|}{ Group $2(n=1178)$} \\
\hline & $n(\%)$ & Age (years) & $n(\%)$ & Age (years) & $p$ overall \\
\hline (a) High risk & $158(14.5)$ & 33.9 & $182(15.4)$ & 33.9 & 0.448 \\
\hline (b) Intermediate risk & $187(17.1)$ & 37.0 & $180(15.3)$ & 37.3 & \\
\hline (c) Low risk & $748(68.4)$ & 32.9 & $816(69.3)$ & 33.3 & \\
\hline
\end{tabular}

Group 1: before the introduction of NIPT; group 2: after the introduction of NIPT. The maternal age (years) is presented by its mean value 
Table 2 Differences in prenatal testing according to risk category before and after the introduction of NIPT

\begin{tabular}{|c|c|c|c|c|c|}
\hline Risk group & Group & $n$ & No further testing & IPT & NIPT \\
\hline \multirow[t]{2}{*}{ (a) High risk } & 1 & 158 & $69(43.7)$ & $89(56.3)$ & $0(0.0)$ \\
\hline & 2 & 182 & $73(40.1)$ & $97(53.3)$ & $12(6.6)$ \\
\hline \multirow[t]{2}{*}{ (b) Intermediate risk } & 1 & 187 & $166(88.8)$ & $21(11.2)$ & $0(0.0)$ \\
\hline & 2 & 180 & $141(78.3)$ & $20(11.1)$ & $19(10.6)$ \\
\hline \multirow[t]{2}{*}{ (c) Low risk } & 1 & 748 & $731(97.7)$ & $17(2.3)$ & $0(0.0)$ \\
\hline & 2 & 816 & 787 (96.4) & $16(2.0)$ & 13 (1.6) \\
\hline
\end{tabular}

Group 1: before the introduction of NIPT; group 2: after the introduction of NIPT. Data are presented as number of patients (\%)

Risk estimation after FTS: (a) high risk $\geq 1: 100$; (b) intermediate risk 1:101-1:1000; (c) low risk $<1: 1000$

$I P T$ invasive prenatal testing, NIPT non-invasive prenatal testing

Table 3 Management choices among high-risk patients after the introduction of NIPT

\begin{tabular}{lcccc}
\hline & Structural abnormality $(n=69)$ & NT $>95$ th percentile $(n=38)$ & Multiple soft markers $(n=43)$ & Normal scan $(n=32)$ \\
\hline IPT & $48(69.6)$ & $21(55.3)$ & $12(27.9)$ & $16(50.0)$ \\
NIPT & $0(0.0)$ & $1(2.6)$ & $3(7.0)$ & $8(25.0)$ \\
No further tests & $21(30.4)$ & $16(42.1)$ & $28(65.1)$ & $8(25.0)$ \\
\hline
\end{tabular}

This table shows the presence or absence of sonographic findings (normal scan) in the high-risk group $(n=182)$ and management choices in the individual subgroups. Data show the number of patients $(\%)$

$I P T$ invasive prenatal testing, NIPT non-invasive prenatal testing

markedly increased nuchal translucency due to the fact that there is a high risk not only for the most common trisomies such as 21, 18 and 13, but also for other less frequent aneuploidies [30, 33]. In fact, $33.3 \%$ of the chromosomal aberrations in our study were numerical or structural other than trisomy 21,18 or 13 .

Our results are in contrast to other studies that report a significant reduction in invasive procedures and concurrently report NIPT rates of 20-30\% in high-risk patients [31, 32, 34, 35]. This discrepancy could be explained by a difference in the study populations, since these patients received genetic counseling and testing primarily because of advanced maternal age or a positive serum screening result [31, 32, 35].

In our setting, NIPT played a rather limited role and only $3.7 \%$ of the study population opted for this method of prenatal screening. Nearly $3 / 4$ of the women choosing NIPT were not considered high risk for fetal aneuploidy, but over $90 \%$ were of advanced maternal age. It seems that NIPT was mostly used as a test for reassurance after a normal ultrasound examination (40/44; $90.9 \%)$. However, among high-risk patients with a normal ultrasound examination, invasive testing was elected twice as often as NIPT. This number certainly is also influenced by the fact that in contrast to NIPT, the costs for IPT are usually covered by insurance companies.

The uptake of NIPT of $3.7 \%$ in our study was lower compared to a recent study from Switzerland where $9 \%$ opted for NIPT [34]. These findings might be due to differences in the health-care systems and also for socioeconomic reasons. Further, the proportion of high-risk patients was lower (6\%) in the Swiss study [34].

We observed a significant decrease in opting for no further testing in women with a risk of $>1: 1000$ after NIPT was available. This decrease was mainly shifted to the utilization of NIPT. Our results are in agreement with those of Chetty et al., who found a decreased likelihood that patients would decline further testing after NIPT became available. Furthermore, they observed an increased uptake of NIPT following abnormal FTS compared to second trimester screening [31].

The proportion of patients choosing an additional test (IPT and NIPT) was significantly higher after the introduction of NIPT in our study, especially in patients with a risk of $>1: 1000$. These findings are in agreement with recent data from Switzerland, reporting a notable increase in prenatal testing after implementation of NIPT [34].

In some US centers that offer NIPT to women of advanced maternal age or abnormal serum screening, the uptake of FTS decreased significantly following the introduction of NIPT. They explained their findings with the patients' preference of NIPT that has higher sensitivity and specificity [32]. This trend however has the disadvantage that fetal malformations and chromosomal anomalies other than trisomy 21, 13 and 18 might escape the diagnosis. In our collective, $33.3 \%$ of the detected fetal aneuploidies by IPT would not have been diagnosed by NIPT. 
Our study shows the clinical implementation of NIPT in a referral center as it found its way into clinical care. The results of our study are certainly influenced by the policies of our health insurance systems that cover the costs of IPT, but do not reimburse NIPT at present. The study, however, reflects the current situation in most European countries. That is also the reason why the uptake is different than that proposed in some screening algorithms [36]. While a general NIPT screening for trisomy 21, 18 and 13 at 10 weeks and FTS at 11-14 weeks was shown to be feasible with a lower false-positive rate compared to combined FTS [36], there is the disadvantage of two appointments with a fetal medicine specialist and the associated costs on top of FTS. Another discussed option is to introduce NIPT based on the results of FTS, similar to the way it was used in our study. This approach, which offers NIPT to a selected population based on the results of FTS, was modeled and showed an increase in the detection rate of trisomy 21 with a decrease of invasive testing [7]. Since FTS will continue to be an essential part of prenatal care and is widely accepted and well established, contingent screening seems to be more reasonable compared to the idea of first-line screening in the "real-world" setting.

In conclusion, the introduction of NIPT in our population was not associated with a decrease of invasive testing. This is most likely due to the high rate of patients with abnormal ultrasound findings and illustrates the benefit of a pre-test ultrasound examination by a specialist for counseling and triage. NIPT is a good option mainly for the exclusion of trisomy 21 in women at an increased risk after FTS in the absence of sonographic findings that have a desire for reassurance and do not want to accept the risks of IPT. Most of these patients opting for NIPT, however, would have chosen no further testing prior to the availability of NIPT. The number of detected aneuploidies by NIPT in this group was low and zero in our study. Uptake is likely to increase further if costs for NIPT decrease and insurance companies start covering the costs for certain risk groups.

Acknowledgments The authors thank Andreas Schötzau, Ute Schubert and Dr. Hans Ulrich Brauer for statistical support, help with data management and critical review of the manuscript.

Conflict of interest The authors declare that there is no conflict of interest.

\section{References}

1. Bianchi DW, Wilkins-Haug L (2014) Integration of noninvasive DNA testing for aneuploidy into prenatal care: what has happened since the rubber met the road? Clin Chem 60(1):78-87

2. Chiu RWK, Lo YMD (2013) Clinical applications of maternal plasma fetal DNA analysis: translating the fruits of 15 years of research. Clin Chem Lab Med 51(1):197-204
3. Sehnert AJ, Rava RP, Bianchi DW (2013) A new era in noninvasive prenatal testing. N Engl J Med 369(22):2164-2165

4. Bianchi DW, Oepkes D, Ghidini A (2014) Current controversies in prenatal diagnosis 1: should noninvasive DNA testing be the standard screening test for Down syndrome in all pregnant women? Prenat Diagn 34(1):6-11

5. Kagan KO, Eiben B, Kozlowski P (2014) Kombiniertes Ersttrimesterscreening und zellfreie fetale DNA: "Next Generation Screening". Ultraschall Med 35(3):229-236

6. Syngelaki A, Pergament E, Homfray T, Akolekar R, Nicolaides KH (2014) Replacing the combined test by cell-free DNA testing in screening for trisomies 21, 18 and 13: impact on the diagnosis of other chromosomal abnormalities. Fetal Diagn Ther 35(3):174-184

7. Nicolaides KH, Wright D, Poon LC, Syngelaki A, Gil MM (2013) First-trimester contingent screening for trisomy 21 by biomarkers and maternal blood cell-free DNA testing. Ultrasound Obstet Gynecol 42(1):41-50

8. Devers P, Cronister A, Ormond K, Facio F, Brasington C, Flodman P (2013) Noninvasive prenatal testing/noninvasive prenatal diagnosis: the position of the national society of genetic counselors. J Genet Couns. 22(3):291-295

9. Benn P, Borell A, Chiu R, Cuckle H, Dugoff L, Faas B et al (2013) Position statement from the Aneuploidy Screening Committee on behalf of the Board of the International Society for Prenatal Diagnosis. Prenat Diagn 33(7):622-629

10. Committee Opinion No. 545 (2012) Noninvasive prenatal testing for fetal aneuploidy. Obstet Gynecol 120(6):1532-1534

11. Kagan KO, Etchegaray A, Zhou Y, Wright D, Nicolaides KH (2009) Prospective validation of first-trimester combined screening for trisomy 21. Ultrasound Obstet Gynecol 34(1):14-18

12. Ekelund CK, Jørgensen FS, Petersen OB, Sundberg K, Tabor A (2008) Impact of a new national screening policy for Down's syndrome in Denmark: population based cohort study. BMJ 337:a2547

13. Wapner R, Thom E, Simpson JL, Pergament E, Silver R, Filkins $\mathrm{K}$ et al (2003) First-trimester screening for trisomies 21 and 18. N Engl J Med 349(15):1405-1413

14. Hagen A, Entezami M, Gasiorek-Wiens A, Albig M, Becker R, Knoll U et al (2011) The impact of first trimester screening and early fetal anomaly scan on invasive testing rates in women with advanced maternal age. Ultraschall Med 32(3):302-306

15. Haddow JE, Palomaki GE, Knight GJ, Cunningham GC, Lustig LS, Boyd PA (1994) Reducing the need for amniocentesis in women 35 years of age or older with serum markers for screening. N Engl J Med 330(16):1114-1118

16. Wray AM, Ghidini A, Alvis C, Hodor J, Landy HJ, Poggi SH (2005) The impact of first-trimester screening on AMA patients' uptake of invasive testing. Prenat Diagn 25(5):350-353

17. Geipel A, Daiss T, Katalinic A, Germer U, Kohl T, Krapp M et al (2007) Changing attitudes towards non-invasive aneuploidy screening at advanced maternal age in a German tertiary care center. Ultraschall Med 28(1):67-70

18. Lüthgens K, Merz E, Hackelöer BJ, Thode C, Eiben B, Kagan KO (2013) Comparison of three first trimester screening algorithms for trisomy 21 with and without adjustment for maternal characteristics. Ultraschall Med 34(2):151-156

19. Nicolaides KH (2011) Screening for fetal aneuploidies at 11 to 13 weeks. Prenat Diagn 31(1):7-15

20. Kagan KO, Wright D, Spencer K, Molina FS, Nicolaides KH (2008) First-trimester screening for trisomy 21 by free beta-human chorionic gonadotropin and pregnancy-associated plasma protein-A: impact of maternal and pregnancy characteristics. Ultrasound Obstet Gynecol 31(5):493-502

21. Chiu R, Akolekar R, Zheng YWL, Leung T, Sun H, Chan K et al (2011) Non-invasive prenatal assessment of trisomy 21 by 
multiplexed maternal plasma DNA sequencing: large scale validity study. BMJ 432:c7401

22. Ehrich M, Deciu C, Zwiefelhofer T, Tynan JA, Cagasan L, Tim R et al (2011) Noninvasive detection of fetal trisomy 21 by sequencing of DNA in maternal blood: a study in a clinical setting. Am J Obstet Gynecol 204(205):e1-e11

23. Sparks AB, Struble CA, Wang ET, Song K, Oliphant A (2012) Non-invasive prenatal detection and selective analysis of cell-free DNA obtained from maternal blood: evaluation for trisomy 21 and trisomy 18. Am J Obstet Gynecol 206(322):e1-e5

24. Palomaki GE, Kloza EM, Lambert-Messerlian GM, Haddow JE, Neveux LM, Ehrich M et al (2011) DNA sequencing of maternal plasma to detect Down syndrome: an international clinical validation study. Genet Med Off $\mathrm{J}$ Am Coll Med Genet. 13:913-920

25. Chen E, Chiu RWK, Sun H, Akolekar R, Chan K, Leung T et al (2011) Noninvasive prenatal diagnosis of fetal trisomy 18 and trisomy 13 by maternal plasma DNA sequencing. PLoS ONE 6(7):e21791

26. Bianchi DW, Platt LD, Goldberg JD, Abuhamad AZ, Sehnert AJ, Rava RP (2012) Genome-wide fetal aneuploidy detection by maternal plasma DNA sequencing. Obstet Gynecol 119:1-13

27. Norton ME, Brar H, Weiss J, Karimi A, Laurent LC, Caughey $\mathrm{AB}$ et al (2012) Non-invasive chromosomal evaluation (NICE) study: results of a multicenter prospective cohort study for detection of fetal trisomy 21 and trisomy 18. Am J Obstet Gynecol 207:1-8

28. Guex N, Iseli C, Syngelaki A, Deluen C, Pescia G, Nicolaides $\mathrm{KH}$ et al (2013) A robust second-generation genome-wide test for fetal aneuploidy based on shotgun sequencing cell-free DNA in maternal blood. Prenat Diagn 33(7):707-710
29. Gil MM, Akolekar R, Quezada MS, Bregant B, Nicolaides KH (2014) Analysis of cell-free DNA in maternal blood in screening for aneuploidies: meta-analysis. Fetal Diagn Ther 35(3):156-173

30. Wellesley D, Dolk H, Boyd PA, Greenlees R, Haeusler M, Nelen $\mathrm{V}$ et al (2012) Rare chromosome abnormalities, prevalence and prenatal diagnosis rates from population-based congenital anomaly registers in Europe. Eur J Hum Genet 20(5):521-526

31. Chetty S, Garabedian MJ, Norton ME (2013) Uptake of noninvasive prenatal testing (NIPT) in women following positive aneuploidy screening. Prenat Diagn 33(6):542-546

32. Friel LA, Czerwinski JL, Singletary CN (2014) The impact of noninvasive prenatal testing on the practice of maternal-fetal medicine. Am J Perinatol 31(9):759-764

33. Kagan KO, Avgidou K, Molina FS, Gajewska K, Nicolaides KH (2006) Relation between increased fetal nuchal translucency thickness and chromosomal defects. Obstet Gynecol 107(1):6-10

34. Manegold-Brauer G, Kang Bellin A, Hahn S, De Geyter C, Buechel J, Hoesli I et al (2014) A new era in prenatal care: noninvasive prenatal testing (NIPT) in Switzerland. Swiss Med Wkly. 144:w13915

35. Platt LD, Janicki MB, Prosen T, Goldberg JD, Adashek J, Figueroa $R$ et al (2014) Impact of noninvasive prenatal testing in regionally dispersed medical centers in the United States. Am J Obstet Gynecol 211(4):368.e1-368.e7

36. Gil MM, Quezada MS, Bregant B, Ferraro M, Nicolaides KH (2013) Implementation of maternal blood cell-free DNA testing in early screening for aneuploidies. Ultrasound Obstet Gynecol 42(1):34-40 